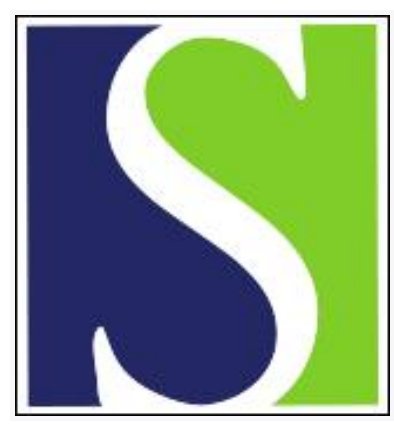

Scand J Work Environ Health 1992;18(1):64-67

https://doi.org/10.5271/sjweh.1607

Issue date: 28 Feb 1992

Mortality study of workers employed by the Italian National Institute of Health, 1960-1989.

by Belli S, Comba P, De Santis M, Grignoli M, Sasco AJ

Affiliation: Istituto Superiore di Sanita, Lab Igiene Ambientale, Rome, Italy.

This article in PubMed: www.ncbi.nlm.nih.gov/pubmed/1553514

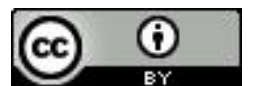




\title{
Mortality study of workers employed by the Italian National Institute of Health, 1960-1989
}

\author{
by Stefano Belli, DSc, ${ }^{1}$ Pietro Comba, DSc, ${ }^{1}$ Marco De Santis, BA,${ }^{1}$ Mario Grignoli, DSc, ${ }^{1}$ \\ Annie J Sasco, MD ${ }^{2}$
}

\begin{abstract}
BELLI S, COMBA P, DE SANTIS M, GRIGNOLI M, SASCO AJ. Mortality study of workers employed by the Italian National Institute of Health, 1960-1989. Scand J Work Environ Health 1992;18:64-7. A cohort mortality study was conducted to evaluate the cancer risk of workers employed by the National Institute of Health in Rome, Italy. Cancer mortality was evaluated for research staff. A deficit of overall cancer mortality was found for the men, but not for the women. Elevated (albeit statistically nonsignificant) standardized mortality ratios were found for cancer of the pancreas (men 155, women 236), cancer of the brain (men 159), lympho- and reticulosarcomas (men 233, women 512), and lymphatic and hematopoietic tumors (women 623). In addition the women had a statistically significantly elevated risk of breast cancer (288). Although most of these results, with the exception of breast cancer among the women, were not statistically significant, due to the limited study size, they point to the existence of excess risks for some tumors. The possibility that these increases are related to exposures occurring in the laboratory setting deserves further consideration.
\end{abstract}

Key terms: brain, breast, cancer risk, lymphomas, occupation, pancreas, research work, sarcomas.

The topic of health risks (infections, reproductive problems, chromosomal abnormalities, and cancer) for research laboratory workers has been the object of a comprehensive review (1). The possibility of an increased risk of cancer among laboratory workers has been raised in several countries by various authors.

A series of reports has concerned subjects who worked in chemical laboratories. $\mathrm{Li}$ et al (2) studied proportionate mortality among members of the American Chemical Society who died in 1948-1967. An excess of pancreatic and lymphohematopoietic neoplasms was observed. Olin \& Ahlbom (3) described mortality patterns among Swedish chemists. Despite low overall mortality, an excess of brain cancer and lymphohematopoietic malignancies was found. Low cancer mortality was reported by Hoar \& Pell (4) in a cohort study of chemists and chemical engineers employed by Dupont. However, a morbidity survey among these workers showed an excess of melanoma. Finally, a cohort study on chemical research workers did not reveal any significant increase in cancer mortality (5). Benzene, other solvents, nitrosated agents, and epoxides are among the agents that have been suggested as potentially responsible for the excess of neoplasms described previously.

1 Istituto Superiore di Sanità, Lab Igiene Ambientale (National Institute of Health, Department of Environmental Health), Rome, Italy.

2 International Agency for Research on Cancer, Unit of Analytical Epidemiology, Lyon, France.

Reprint requests to: Dr S Belli, Istituto Superiore di Sanità, Lab Igiene Ambientale, viale Regina Elena 299, I-00161 Rome, Italy.
A group of relatively recent studies describes the occurrence of brain cancer, especially glioblastoma, among biology research workers and dentists. A cluster of three cases of glioblastoma was reported among approximately 100 workers in a genetics laboratory (6). All three of the workers had used mutagenic agents, in particular methylnitronitrosoguanidine. Increased mortality due to brain cancer was reported by Harrington \& Oakes (7) for pathologists working in hematology. An increased incidence of glioblastoma was described by Ahlbom et al (8) for Swedish dentists and dental nurses. Finally, a cluster of cancer cases, especially lymphomas and sarcomas, was detected among subjects engaged in molecular biology, genetics, and mutagenicity testing in the Pasteur Institute in Paris. An epidemiologic study is in progress there (9).

Since 1987, an epidemiologic study has been examining mortality patterns of persons employed by the Italian National Institute of Health (Istituto Superiore di Sanità). The study of cause-specific mortality among the employees was intended to provide new evidence regarding increased cancer risks among laboratory workers.

The Institute was created in the 1930 s as a public health facility mainly aimed at the study of malaria, and the departments of parasitology, microbiology, and pharmacology were started at that time. Subsequently, the field of interest was expanded to include food safety, drug, environmental, and biomedical research. Approximately 1500 persons are currently employed by the Institute. Taking into account latency time, this study should be able to provide information relating to carcinogenic exposures that occurred at the Institute in the 1940s-1960s. Radioactive material, 
solvents, chemical mutagens, and viruses can be regarded as agents of possible etiologic relevance.

The methodology adopted in the present investigation was a retrospective cohort study, a choice consistent with the recommendations of the International Agency for Research on Cancer (10), which is currently engaged in a multicenter study of cancer risk in biologically oriented research laboratories.

\section{Subjects and methods}

The cohort included all subjects working at the National Institute of Health on 1 January 1960 and those who were subsequently employed there until 30 June 1989. The information collected for each subject included name, gender, and dates of birth, hiring and termination. On the basis of the employment records, the job category for each subject was also available. The two major job categories of research and administration were considered, the former including scientists of any degree, laboratory technicians, and maintenance workers and the latter including people working in administrative or secretarial positions. The present contribution deals with the former group. Altogether 1797 subjects were included in the cohort, 1112 men and 685 women. The follow-up period was from 1 January 1960 through 30 June 1989. We ascertained the vital status and cause of death of the cohort members as of 30 June 1989 by consulting the death registers of the population office of the city of Rome. The underlying cause of death was coded according to the eighth (deaths occurring before 1980) or ninth (deaths occurring from 1980 on) revision of the International Classification of Diseases. When a subject had moved to another town, a postal search was started, and the population office of the place of residence was asked to give information about the vital status and the cause of death of the subject.

The data have been analyzed with a package provided by the United States National Institute for Occupational Safety and Health (11). Person-years were calculated according to age (five-year age groups), gender, calendar time (five-year time periods), and induction or latency time (computed from start of employment). The mortality experience of the cohort was compared with that expected for the Italian population, cause-, gender-, age- and calendar-specific mortality rates being applied. A Poisson distribution was assumed for the observed numbers of deaths. The results are presented in terms of standardized mortality ratios with $95 \%$ confidence limits.

\section{Results}

Table 1 shows the age distribution of the cohort, table 2 gives the results of the follow-up with respect to survival status, and table 3 presents the distribution of the subjects by year of employment. As can be seen, the vital status of $99.4 \%$ of the population was ascertained. The very few lost subjects were treated as still alive. The cause of death of four subjects $(2.0 \%$ of the deceased) could not be established.

Table 4 shows the mortality experience of the cohort. For neither the men nor the women was there any major trends when overall mortality was examined with respect to calendar time or induction latency time, and a similar pattern was shown for cancer mortality.

Among the men, mortality from all causes and from all cancers was significantly lower than expected. Nonsignificant increases of pancreatic cancer, brain cancer, and lymphohematopoietic malignancies were detected, and one case of soft-tissue sarcoma was found. The excess of pancreatic cancer was not concentrated in any particular time period, and most cases appeared after 20-30 years of latency. The excess of lymphohematopoietic malignancies was related to neither calendar time nor latency.

Mortality due to diseases of the circulatory system, respiratory diseases, and liver cirrhosis was lower than expected. A significant increase in diabetes was observed, however.

Among the women mortality from all causes and from circulatory and respiratory diseases was lower than expected. There was an increase in cancer mortality mainly due to a significant excess of breast cancer. However, the cases we observed do not seem to

Table 1. Distribution of person-years of the cohort by age and gender.

\begin{tabular}{lcc}
\hline Age (years) & Men $(\mathrm{N})$ & Women $(\mathrm{N})$ \\
\hline$<34$ & 4143 & 2834 \\
$35-44$ & 5355 & 2450 \\
$45-54$ & 4828 & 1866 \\
$\geq 55$ & 5321 & 2022 \\
\hline Total & 19647 & 9172 \\
\hline
\end{tabular}

Table 2. Survival status of the cohort members.

\begin{tabular}{lcc}
\hline Status & Men (N) & Women (N) \\
\hline Alive & 942 & 645 \\
Dead & 163 & 36 \\
Unknown & 7 & 4 \\
\hline Total & 1112 & 685 \\
\hline
\end{tabular}

Table 3. Distribution of the subjects by year of employment.

\begin{tabular}{lrrrrr}
\hline Year of employment & \multicolumn{2}{c}{ Men } & & \multicolumn{2}{c}{ Women } \\
\cline { 2 - 3 } \cline { 5 - 6 } & $\mathrm{N}$ & $\%$ & & $\mathrm{~N}$ & $\%$ \\
\hline Before 1951 & 159 & 14.3 & & 51 & 7.4 \\
$1951-1960$ & 172 & 15.5 & & 62 & 9.1 \\
$1961-1970$ & 310 & 27.8 & & 122 & 17.8 \\
$1971-1980$ & 219 & 19.7 & & 148 & 21.6 \\
After 1980 & 252 & 22.7 & & 302 & 44.1 \\
\hline Total & 1112 & 100.0 & & 685 & 100.0 \\
\hline
\end{tabular}


Table 4. Mortality experience of the cohort.

\begin{tabular}{|c|c|c|c|c|c|c|c|c|}
\hline \multirow[b]{2}{*}{ Cause of death } & \multicolumn{4}{|c|}{ Men } & \multicolumn{4}{|c|}{ Women } \\
\hline & $\begin{array}{l}\text { Observed } \\
\text { (N) }\end{array}$ & $\begin{array}{l}\text { Expected } \\
\qquad(\mathrm{N})\end{array}$ & $\begin{array}{c}\text { Stan- } \\
\text { dardized } \\
\text { mortality } \\
\text { ratio }\end{array}$ & $\begin{array}{c}95 \% \\
\text { confidence } \\
\text { interval }\end{array}$ & $\begin{array}{l}\text { Observed } \\
\text { (N) }\end{array}$ & $\begin{array}{l}\text { Expected } \\
(\mathrm{N})\end{array}$ & $\begin{array}{c}\text { Stan- } \\
\text { dardized } \\
\text { mortality } \\
\text { ratio }\end{array}$ & $\begin{array}{c}95 \% \\
\text { confidence } \\
\text { interval }\end{array}$ \\
\hline All cancers & 37 & 57.6 & 64 & $45-89$ & 16 & 13.3 & 120 & $69-195$ \\
\hline Cancer of stomach & 6 & 7.7 & 77 & $28-169$ & - & 1.4 & 0 & $0-264$ \\
\hline $\begin{array}{l}\text { Intestine } \\
\text { Biliary passages and liver } \\
\text { Pancreas } \\
\text { Larynx } \\
\text { Trachea, bronchus and lung } \\
\text { Prostate } \\
\text { Kidney } \\
\text { Bladder } \\
\text { Brain } \\
\text { Lymphosarcoma and reticulosarcoma } \\
\text { Hodgkin's disease } \\
\text { Leukemia and aleukemia } \\
\text { Lymphatic and hematopoietic tissue }\end{array}$ & $\begin{array}{r}1 \\
3 \\
1 \\
12 \\
2 \\
1 \\
1 \\
2 \\
2 \\
1 \\
2\end{array}$ & $\begin{array}{r}3.4 \\
2.2 \\
1.9 \\
2.3 \\
17.1 \\
2.5 \\
1.0 \\
2.3 \\
1.3 \\
0.9 \\
0.7 \\
1.8\end{array}$ & $\begin{array}{r}29 \\
0 \\
155 \\
43 \\
70 \\
79 \\
99 \\
42 \\
159 \\
233 \\
152 \\
112\end{array}$ & $\begin{array}{r}1-162 \\
0-168 \\
32-454 \\
1-242 \\
36-123 \\
10-288 \\
3-555 \\
1-239 \\
19-575 \\
28-843 \\
4-848 \\
14-408\end{array}$ & $\begin{array}{l}1 \\
1 \\
1 \\
2 \\
8 \\
- \\
- \\
-1 \\
-\end{array}$ & $\begin{array}{l}1.1 \\
0.6 \\
0.4 \\
0.0 \\
0.8 \\
2.8 \\
0.2 \\
0.2 \\
0.3 \\
0.2 \\
0.2 \\
0.5\end{array}$ & $\begin{array}{r}89 \\
161 \\
236 \\
257 \\
288 \\
0 \\
0 \\
0 \\
512 \\
0 \\
0\end{array}$ & $\begin{array}{c}2-496 \\
4-897 \\
6-1312 \\
\\
31-930 \\
124-568 \\
0-1845 \\
0-1845 \\
0-1230 \\
13-2845 \\
0-1845 \\
0-738\end{array}$ \\
\hline $\begin{array}{l}\text { (other) } \\
\text { Other malignant neoplasms }\end{array}$ & $\overline{3}$ & $\begin{array}{r}0.6 \\
11.8\end{array}$ & $\begin{array}{r}0 \\
25\end{array}$ & $\begin{array}{l}0-615 \\
5-74\end{array}$ & $\begin{array}{l}1 \\
1\end{array}$ & $\begin{array}{l}0.2 \\
4.3\end{array}$ & $\begin{array}{r}623 \\
23\end{array}$ & $\begin{array}{c}16-3462 \\
1-130\end{array}$ \\
\hline Benign neoplasms & - & 0.1 & 0 & $0-3689$ & - & 0.1 & 0 & $0-3689$ \\
\hline Diabetes mellitus & 9 & 3.8 & 238 & $109-454$ & 3 & 1.9 & 155 & $32-456$ \\
\hline Diseases of circulatory system & 68 & 79.8 & 85 & $66-108$ & 8 & 20.7 & 38 & $17-76$ \\
\hline Diseases of respiratory system & 10 & 14.9 & 66 & $32-123$ & 1 & 2.3 & 43 & $1-239$ \\
\hline Cirrhosis of liver & 6 & 12.5 & 47 & $17-104$ & 2 & 1.6 & 122 & $15-443$ \\
\hline Diseases of genitourinary system & 4 & 3.2 & 124 & $34-319$ & 1 & 0.7 & 138 & $4-771$ \\
\hline Accidents & 7 & 13.1 & 53 & $21-110$ & 2 & 1.7 & 115 & $14-415$ \\
\hline Violence & 1 & 2.4 & 41 & $1-230$ & - & 0.4 & 0 & $0-922$ \\
\hline Other causes & 21 & 15.9 & 132 & $82-202$ & 3 & 4.4 & 68 & $14-199$ \\
\hline All causes & 163 & 203.2 & 80 & $68-93$ & 36 & 47.0 & 76 & $54-106$ \\
\hline
\end{tabular}

have a common origin in time, and most of them appeared $10-20$ years after the start of exposure. Increases in lung cancer and lymphohematopoietic malignancies were found, but the standardized mortality ratios were based on very few cases. One case of pancreatic cancer was reported.

Of the nonmalignant diseases, an excess was found for diabetes mellitus; it was not statistically significant, however.

\section{Discussion}

The validity aspects of the study deserve some comments. First, data completeness appears to be satisfactory and follow-up was successful for over $99 \%$ of the cohort members.

Information on the cause of death was uniformly collected for all of the cohort members from the population offices of the city of Rome and the other cities to which subjects had moved. The proportion of subjects with an unknown cause of death $(2.0 \%)$ was very low.

The use of the general population as a reference entity in cohort studies has been extensively discussed (12-14). National rates rather than local rates were used for the estimation of expected figures in the present study, essentially because the cohort was made up of people who moved to Rome from various parts of Italy and thus reflected different background rates of occurrence of disease. The choice was thus a matter of validity. Secondly, it should be noted that some of the outcomes of interest (namely, brain cancer, pancreatic cancer, and lymphohematopoietic malignancies) are rare diseases, and national rates have a greater stability than regional rates since they are based on a larger population and thus provide more precise expected figures. A low mortality from all causes has been detected in other investigations of laboratory workers $(3-5,7,9)$, and it has been ascribed to favorable social conditions and health consciousness. In this particular cohort, the low mortality from liver cirrhosis and the lack of any excess of lung cancer among the men may indicate a low consumption of alcohol and tobacco, which is compatible with a health-conscious life-style.

Moderate excesses of specific neoplasms were detected in this study. These findings are of interest for their possible association with carcinogenic exposures in the laboratories, although the role of chance should not be overlooked whenever multiple comparisons are performed. Caution is required in interpreting the finding of excess pancreatic cancer, however, since the agreement between the diagnosis of pancreatic cancer from death certificates and autopsies has been estimated as being only about $40 \%$, mainly because pancreatic cancer is underreported on death certificates (15). The accuracy of death certificates has been shown to be higher in the 1980s than in the 1970s however. There was no available evidence of differential reporting of pancreatic cancer on the death certificates of the members of this particular cohort with respect 
to the general population, as there was no evidence of differential availability of medical care leading to unequal diagnostic accuracy, even if such possibilities cannot be ruled out.

As has already been mentioned, excesses of lymphohematopoietic malignancies were reported by $\mathrm{Li}$ et al (2) and Olin \& Ahlbom (3). In addition the preliminary findings of the Pasteur Institute study seem to show consistent figures (9).

The statistically significant increase in breast cancer mortality deserves some comment. The major risk factors for breast cancer are hormones, diet, and reproductive history $(16,17)$. Ionizing radiation, including low-level diagnostic radiation, is a risk factor for breast cancer $(18,19)$, although information on breast cancer among women occupationally exposed to radioactive products in laboratories is not available. A similar excess has already been described for the female members of the American Chemical Society (20). A different reproductive life of working women with a high level of education could account for part or most of the differences observed by comparison with the general population. In the absence of any data on the reproductive life of these subjects or on precise occupational exposures, we cannot currently conclude what the etiology of the cases differ from cancer of the breast in the general population.

The significant excess of mortality from diabetes among men, unlike the excess of the aforementioned neoplasms, does not seem to be related to the work environment of research laboratories according to a priori evidence. The finding is thus reported without any particular suggestion on its possible etiologic meaning.

In light of our observations, a major cancer risk among employees of the Italian National Institute of Health can be ruled out. The excesses of lymphohematologic malignancies and brain and pancreatic cancer appear to be consistent with observations from other occupational investigations, while the excess of breast cancer is likely to be related to personal risk factors, such as reproductive history.

\section{Acknowledgments}

Preliminary results of this study were presented at the XIII Réunion du Groupe pour l'épidémiologie et l'enregistrement du cancer dans les pays de langue latine (Pamplona, Spain, May 12-13, 1988).

This study was supported by a grant from the European Commission in the framework of the "Europe against Cancer" program (convention 880516 between the EEC and the International Agency for Research on Cancer).

The authors thank Dr R Saracci for his advice on this study, Dr A Masina for his qualified contribution, and Dr $\mathbf{J}$ Cheney for his editorial assistance.

\section{References}

1. Sasco AJ. Risques pour la santé dans les laboratoires de recherche biologique et médicale. Méd Sci 1989;5: 489-98.

2. Li FP, Fraumeni JF, Mantel N. Cancer mortality among chemists. J Natl Cancer Inst 1969;43:1159-64.

3. Olin GR, Ahlbom A. The cancer mortality among Swedish chemists graduated during three decades. Environ Res 1980;22:154-61.

4. Hoar SK, Pell S. A retrospective cohort study of mortality and cancer incidence among chemists. J Occup Med 1981;23:485-94.

5. Maher KV, Defonso LR. A historical cohort study of mortality among chemical researchers. Arch Environ Health 1986;41:109- 16.

6. Pleven C, Audran R, Falcy M. Glioblastomes et mutagenèse chimique dans les laboratoires de biologie. Arch Mal Prof Méd Trav Sécur Soc 1983;44:411-8.

7. Harrington JM, Oakes D. Mortality study of British pathologists 1974-80. Br J Ind Med 1984;41:188-91.

8. Ahlbom A, Norell S, Rodval Y, Nylander M. Dentists, dental nurses, and brain tumors. Br Med J 1986;292:662.

9. Cordier S. Risk of cancer among laboratory workers. Lancet 1990;1:1097.

10. Sasco AJ, Muir CS, Saracci R. IARC international study of cancer risk in biology research laboratory workers: proposed protocol. Lyon: International Agency for Research on Cancer, 1986.

11. Waxweiler RJ, Beaumont JJ, Henry JA. A modified life table analysis system for cohort studies. J Occup Med 1983;25:115-24

12. Wang JD, Miettinen OS. Occupational mortality studies: principles of validity. Scand J Work Environ Health 1982;8:153-8.

13. Gardner MJ. Consideration in the choice of expected numbers for appropriate comparisons in occupational cohort studies. Med Lav 1986;77:23-47.

14. Monson RR. Observations on the healthy worker effect. J Occup Med 1986;28:425-33.

15. Riboli E, Stanta G, Delendi M, Gardinan D, Peruzzo $\mathrm{P}$, Sasco AJ, et al. Comparison between diagnoses of cancers of stomach, colon, rectum, gall-bladder, liver and pancreas on death certificates and at autopsy in Trieste, 1970-1984. In: Riboli E, Delendi M, ed. Autopsy in epidemiology and medical research. Lyon: International Agency for Research on Cancer, 1991: 45-54. (IARC scientific publication; no 112.)

16. Toti A, Agugiaro S, Amadori D, Buzzi G, Bruzzi P, Buiatti E. Breast cancer risk factors in Italian women: a multicentric case-control study. Tumori $1986 ; 72$ : 241-9.

17. Negri E, La Vecchia C, Bruzzi P, Dardanoni G, Decarli A, Palli D, et al. Risk factors for breast cancer: pooled results from three Italian case-control studies. Am J Epidemiol 1988;128:1207-15.

18. Hoffman DA, Lonstein JE, Morin MM, Visscher W, Harris BSJ, Boice JD. Breast cancer in women with scoliosis exposed to multiple diagnostic $\mathrm{x}$ rays. J Natl Cancer Inst 1989;81:1307-12.

19. Tokunaga M, Land CE, Yamamoto T, Asano M, Tokuoka S, Ezaki M, et al. Incidence of female breast cancer among atomic bomb survivors, Hiroshima and Nagasaki, 1950-1980. Radiat Res 1987;112:243-72.

20. Walrath J, Li FP,Hoar SK, Mead MW, Fraumeni JF. Causes of death among female chemists. Am J Public Health $1985 ; 15: 883-5$.

Received for publication: 14 November 1990 